\title{
Beyond BMI: Conceptual Issues Related to Overweight and Obese Patients
}

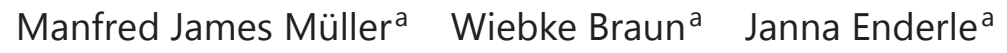 \\ Anja Bosy-Westphal ${ }^{b}$ \\ anstitute of Human Nutrition and Food Science, Christian-Albrechts-University, Kiel,

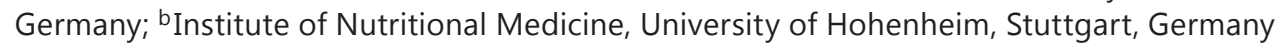

\section{Key Words}

Nutritional status · Body composition · Cardiometabolic risks · Phenotype

\begin{abstract}
$\mathrm{BMI}$ is widely used as a measure of weight status and disease risks; it defines overweight and obesity based on statistical criteria. BMI is a score; neither is it biologically sound nor does it reflect a suitable phenotype worthwhile to study. Because of its limited value, BMI cannot provide profound insight into obesity biology and its co-morbidity. Alternative assessments of weight status include detailed phenotyping by body composition analysis (BCA). However, predicting disease risks, fat mass, and fat-free mass as assessed by validated techniques (i.e., densitometry, dual energy $X$ ray absorptiometry, and bioelectrical impedance analysis) does not exceed the value of BMI. Going beyond BMI and descriptive BCA, the concept of functional body composition ( $\mathrm{FBC}$ ) integrates body components into regulatory systems. $\mathrm{FBC}$ refers to the masses of body components, organs, and tissues as well as to their inter-relationships within the context of endocrine, metabolic and immune functions. FBC can be used to define specific phenotypes of obesity, e.g. the sarcopenic-obese patient. Well-characterized obesity phenotypes are a precondition for targeted research (e.g., on the genomics of obesity) and patient-centered care (e.g., adequate treatment of individual obese phenotypes such as the sarcopenic-obese patient). FBC contributes to a future definition of overweight and obesity based on physiological criteria rather than on body weight alone.
\end{abstract}


Müller et al.: Beyond BMI: Conceptual Issues Related to Overweight and Obese Patients

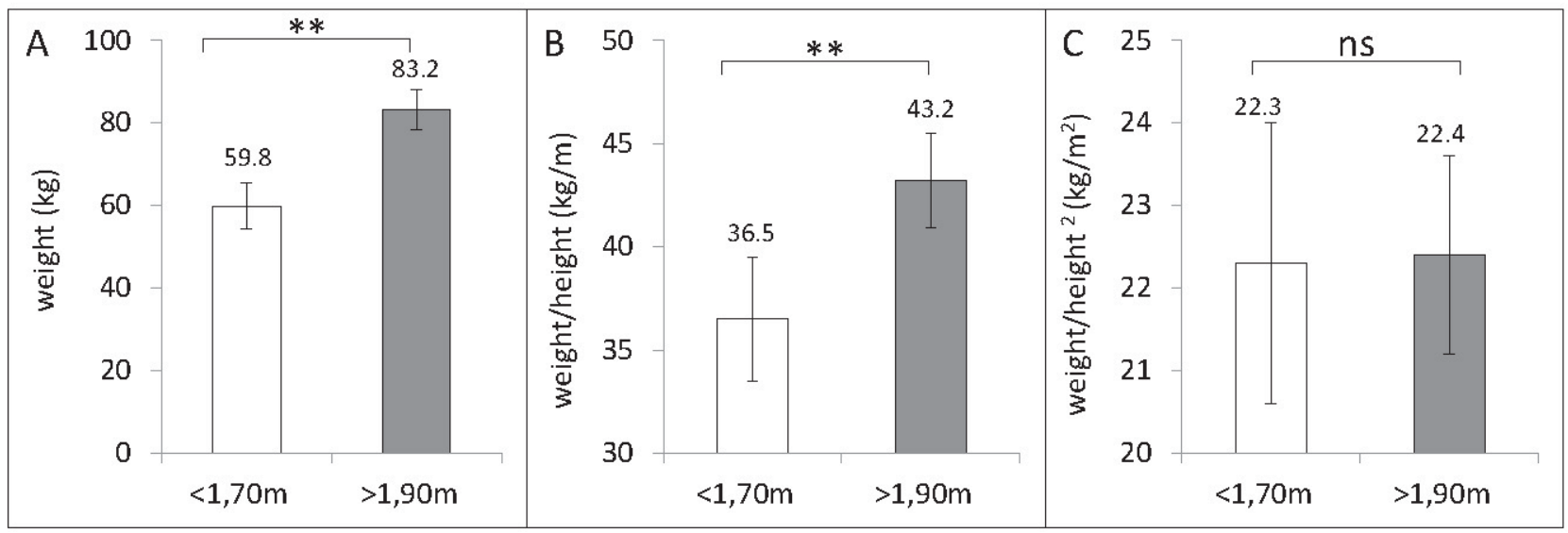

Fig. 1. Body weight (A), weight-to-height ratio (B), and BMI (weight/height, $\mathrm{kg} / \mathrm{m}^{2}$; C) in a group of 125 normal-weight adults (mean age: 41.5 years; mean body weight: $62.5 \mathrm{~kg}$ ) differing in height. When compared with smaller subjects, taller subjects were heavier and their weight-to-height ratio was higher. By contrast, small and tall subjects had a nearly identical BMI. Data were taken from the population data base of the German Reference Centre of Body Composition, Kiel.

\section{History of BMI}

In 1835, BMI (calculated from body weight in kilogram divided by square of height in meter; $\mathrm{kg} / \mathrm{m}^{2}$ ) was first introduced by Adolphe Quetelet, a Belgian astronomer, mathematician and statistician [1], and thus was formerly referred to as the Quetelet's index. BMI is a mathematical construct. Quetelet demonstrated that i) adult weight increases proportional to height squared and ii) BMI provides a stature-independent measure of body weight, allowing to compare the body weight of short and tall subjects. The original concept was extended during the second half of the 20th century by Ancel Keys [2], who discovered that BMI correlated with body fat mass (FM) as derived from either skin folds or body density measurements. Keys assumed that quantitative weight-height relationships are essential in scientific research on body mass, fatness, and obesity-related disease risks. In adults, BMI was found to be preferable over other indices of relative weight: BMI had the lowest correlation with height but the highest correlation with body fat; it was simple to calculate and applicable to every population at all times. In 1980, Reuben Andres [3] recommended to use BMI in clinical studies on the occasion of the Association of Life Insurance Medical Directors Annual Meeting in New York. BMI is still a central aspect in the current weight-for-height guidelines of the World Health Organization (WHO) and of the US National Heart, Lung and Blood Institute $[4,5]$.

\section{Use of BMI}

Today, BMI is widely used for routine characterization of weight status in epidemiology, clinical nutrition, and research, not least because it is simple to measure and regularly documented in individual health records. In adults, BMI is a stature-independent measure of body weight (fig. 1) and a surrogate measure of total body fat (fig. 2A, B). BMI is used to classify subjects into the categories 'underweight' $\left(<18.5 \mathrm{~kg} / \mathrm{m}^{2}\right)$, 'normal weight' ( $>18.5$ and $<25.0$ $\left.\mathrm{kg} / \mathrm{m}^{2}\right)$, 'overweight' $\left(>25 \mathrm{~kg} / \mathrm{m}^{2}\right)$ or 'obese' $\left(>30 \mathrm{~kg} / \mathrm{m}^{2}\right)[4,5]$. Obesity is further graduated 


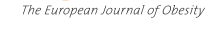

Müller et al.: Beyond BMI: Conceptual Issues Related to Overweight and Obese Patients
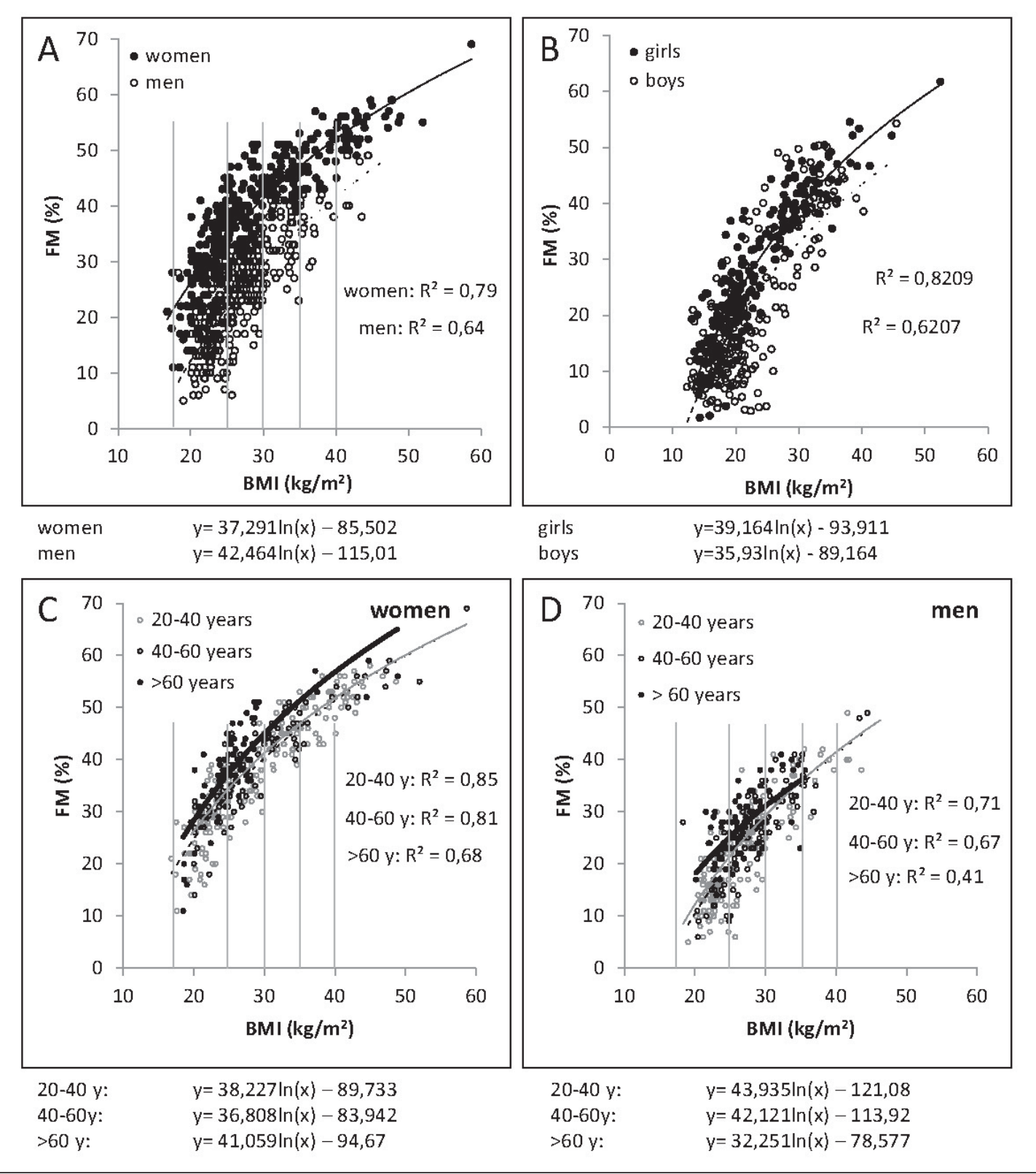

Fig. 2. Association between BMI and percentage FM in adults ( $\mathrm{n}=375$ women, 332 men; $\mathbf{A})$ and children and adolescents ( $\mathrm{n}=228$ girls, 202 boys; B) as well as in younger and older women (C) and men (D). The association is curve-linear and differs in males and females as well as in different age groups. Body fat was measured by air displacement plethysmography. Data were taken from the population data base of the German Reference Center of Body Composition, Kiel.

into class $1\left(>30-35 \mathrm{~kg} / \mathrm{m}^{2}\right)$, class $2\left(>35-40 \mathrm{~kg} / \mathrm{m}^{2}\right)$, and class $3\left(>40 \mathrm{~kg} / \mathrm{m}^{2}\right)$. These categories comprise people with differences in nutritional status, age, sex, lifestyle, physical functioning, disease risks as well as ethnic and genetic backgrounds.

In children, international BMI growth charts were developed [6]. Age- and sex-specific cut-offs were defined based on statistical analyses; the 85th, 90th, 95th and 97th centiles are used to define overweight and obesity. However, BMI is not independent of the stature during 
Müller et al.: Beyond BMI: Conceptual Issues Related to Overweight and Obese Patients

infancy and puberty. In order to give an index of relative weight independent of height for age, the appropriate power (p) of height was calculated to be at about 2 in pre-school children, but $p$ gradually increased up to 3 until age 11 and fell back again to 2 thereafter [7]. Accordingly, p of height, used to score the lowest correlation coefficient with height, was smallest at 12 months of age (i.e., 1.5) and largest at 8-12 years of age (i.e., 3.1) [8]. When using $\mathrm{kg} / \mathrm{m}^{2}$ instead of appropriate age-dependent adjustments, tall and physically advanced children may be falsely categorized as overweight during puberty.

Today, overweight and obesity are defined by statistical criteria. Normal BMI values refer to Caucasian, African and Hispanic populations; by contrast, lower cut-offs have been proposed for Asians [9]. BMI categorization relates to data from reference populations or data gained by drawing upon the U-shaped (with increased risks at both ends of the BMI scale) or J-shaped (increased risk at high BMI only) relations between BMI and either cardiometabolic risks or mortality [10]. It was calculated that an increase in BMI of $5 \mathrm{~kg} / \mathrm{m}^{2}$ was associated with a $30 \%$ increase in total mortality [10]. In non-Asian populations, the BMI category with the lowest mortality risk is between 22.0 and $24.9 \mathrm{~kg} / \mathrm{m}^{2}$, with an increase in mortality below and above that range [10]. Considering smoking status, preexisting disease or early mortality has little effect on BMI with minimal mortality $[10,11]$. The normal range of BMI is not altered by sex. In Asian populations, underweight was associated with the highest risk of death, whereas a high BMI showed no significant risk in some East Asian populations $[12,13]$.

\section{Critics of BMI}

\section{Is There an Optimal BMI?}

Scientifically, BMI is a crude means to characterize disease risks. In addition, large-scale studies suggest that a high BMI-associated disease risk does not necessarily result in a higher mortality $[14,15]$. Contrary to class 2 and 3 obesity, overweight and class 1 obesity did not increase the mortality risk [14], thus questioning i) the value of BMI as a health risk surrogate, ii) the definition of overweight and class 1 obesity as well as iii) the need of treatment for these patient groups. In fact, the lowest mortality was observed in the overweight group compared to normal-weight groups, with a nadir of the all-cause mortality BMI curve between 24.0 and $30.9 \mathrm{~kg} / \mathrm{m}^{2}[14,15]$. Thus, the optimal BMI associated with the lowest mortality rate was within the range of overweight and obesity. In addition, in older people, mortality increased at a $\mathrm{BMI}<23 \mathrm{~kg} / \mathrm{m}^{2}$ (which is within the normal BMI range defined by the WHO) [15]. Above the age of 70 years, the lowest mortality was observed in overweight and class 1 obese subjects $[3,16]$. Altogether, these data suggest that the optimal BMI has to be defined according to individual age, ethnicity, and chronic diseases (see below).

\section{Is There a True 'Obesity Paradox'?}

Although obesity is considered a risk factor for chronic diseases (e.g., for some cancer types), a BMI $>30 \mathrm{~kg} / \mathrm{m}^{2}$ paradoxically appeared to be protective for survival in patients with chronic and wasting diseases (e.g., cancer) $[17,18]$. This finding suggests that in cancer patients the BMI associated with the highest survival rate is within the range of overweight or even obesity. However, the so-called 'obesity paradox' was only observed in cancer patients when obesity was defined by BMI [19]. By contrast, body composition analysis (BCA) identified an increased mortality risk in obese cancer patients with a low skeletal muscle mass and a protective effect in obese patients with normal muscle mass only [19]. However, these observational data does not allow a differentiation between low muscle mass or a high FM to fat-free mass (FFM) ratio in order to explain increased mortality in sarcopenic-obese cancer 
Müller et al.: Beyond BMI: Conceptual Issues Related to Overweight and Obese Patients

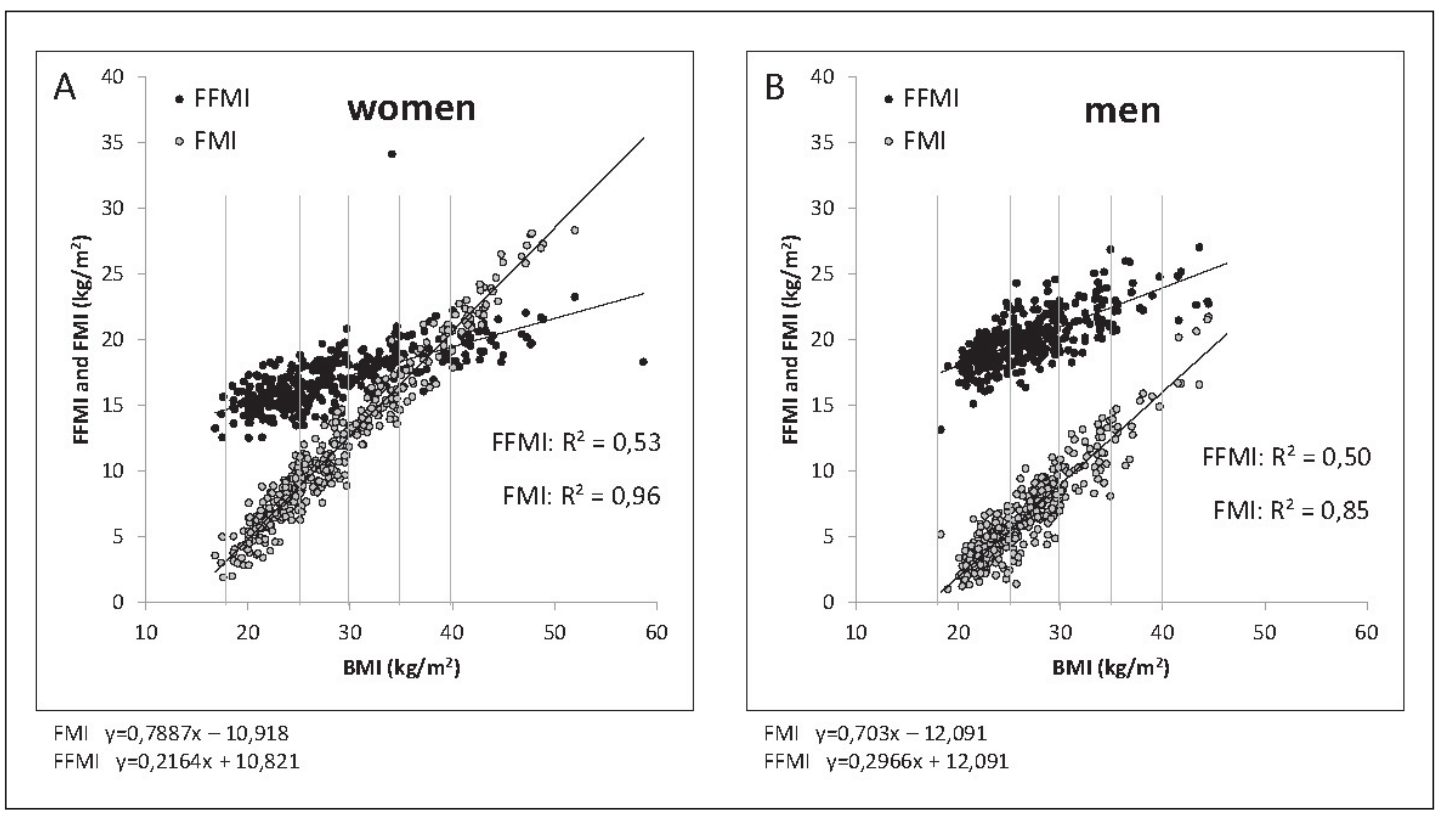

Fig. 3. Association between BMI and height-squared adjusted FM (fat mass index (FMI) and fat free mass index (FFMI)) in women ( $\mathrm{n}=375$; A) and men ( $\mathrm{n}=332$; B). Both, FMI and FFMI increase with BMI; thus, BMI is non-specific predicting body composition. Body composition was assessed by air displacement plethysmography. Data were taken from the population data base of the German Reference Center of Body Composition, Kiel.

patients. Obviously, BMI cannot reflect the prognostic effects of low muscle mass and/or a high FM-FFM ratio. Therefore, the idea of an 'obesity paradox' is misleading.

\section{Can BMI Reflect Body Composition?}

BMI is a weak and indirect measure of body composition. BMI is correlated with FM (fig. 2, 3) and FFM (fig. 3). Both FM and FFM increase with a rising BMI. Correlation coefficients relating BMI to FM and FFM are similar (i.e., BMI is a nonspecific predictor of body composition), but regression lines differ in slopes (fig. 3). In addition, the association between BMI and percentage FM is curve-linear (fig. 2). Comparing different body weight categories, the relationship between BMI and FM differs between normal-weight and underweight individuals; the strongest association is seen in obese subjects (fig. 2A). With a given BMI, interindividual variances of FM and FFM are high, for example, FM may vary by more than $100 \%$ [15] (fig. 2A). In addition, differences in sex and age influence the strength of the association between BMI and FM, with higher increases in FM per BMI unit seen in women and in the elderly (fig. 2C, D).

BMI being a measure of general adiposity can neither address fat distribution nor discriminate the ratio of fat to lean mass [20]. Both, waist circumference (WC) (as an indirect measure of abdominal or visceral adipose tissue (VAT)) $[21,22]$ and waist-to-hip ratio (WHR) (the ratio of WC to hip circumference as a measure of fat distribution) [22, 23] have BMI-independent effects on cardiometabolic risk. For risk assessment, it is recommended to use WC in combination with BMI in overweight and class 1 obese subjects [4, 5]. BMI, WC, and WHR have similar correlations to coronary heart disease and ischemic stroke [23].

BMI, WC, and WHR are correlated with each other (i.e., $r=0.85$ between BMI and WC, $r=0.43$ between BMI and WHR, and $r=0.70$ between WC and WHR; data were adjusted for 
Müller et al.: Beyond BMI: Conceptual Issues Related to Overweight and Obese Patients

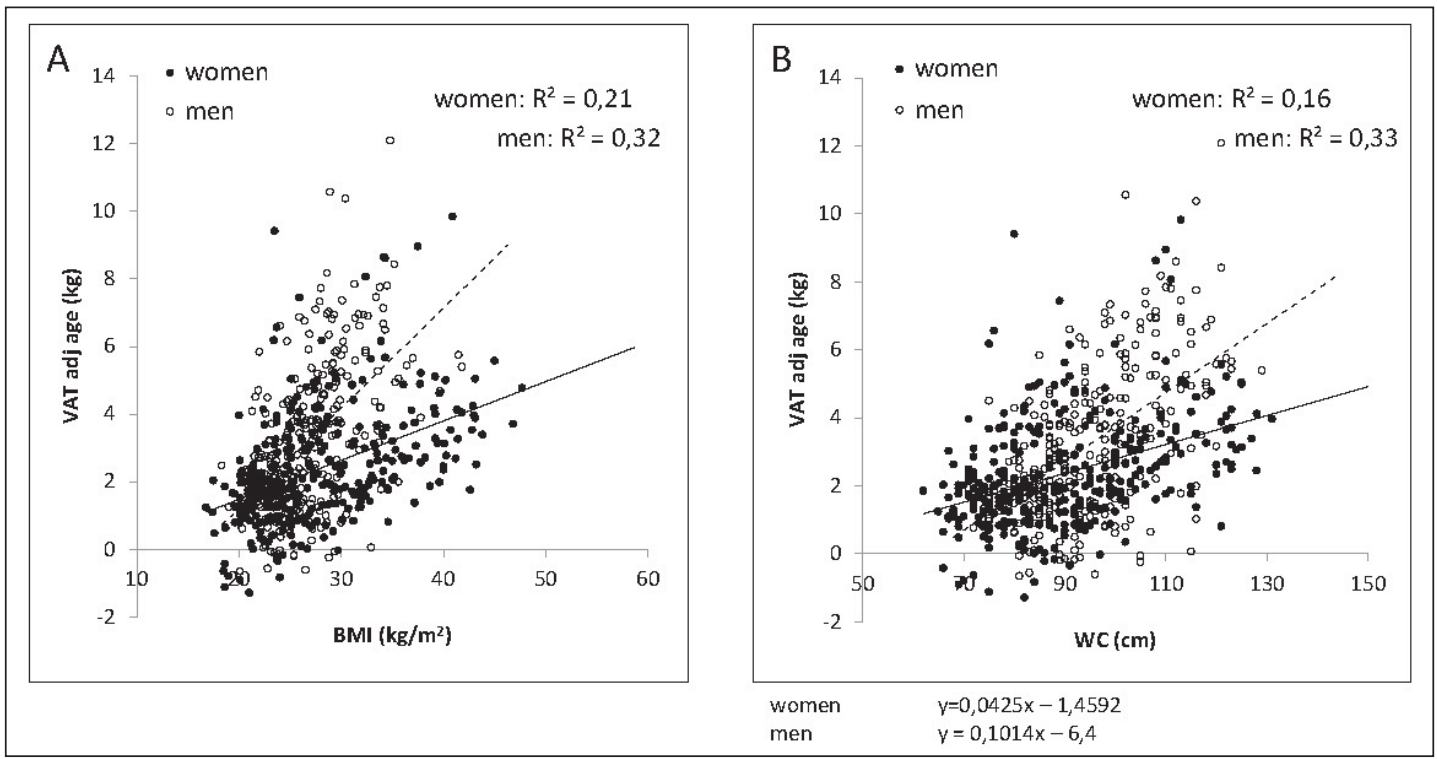

Fig. 4. Associations between BMI (A), WC (B), and MRI-determined VAT adjusted for age in 327 women and 302 men. There are positive associations between either BMI or WC and VAT. Data were taken from the population data base of the German Reference Center of Body Composition, Kiel.

age and sex) [23]. In addition, there are significant correlations between either BMI or WC and VAT (fig. 4). Using a multiple regression analysis with VAT as dependent variable, BMI explained $32 \%$ of the variance without an additional effect of WC. Furthermore, neither WC nor VAT itself correlated with liver fat [24]. The present evidence suggests that in overweight and obese patients ectopic fat in the liver rather than VAT determines cardiometabolic risk [24]. In summary, BMI and WC are crude estimates of body composition, metabolic functions, and disease risks associated with individual body components.

\section{Uncritical Use of BMI in Genetic Studies}

The characteristics of obesity considered suitable for measurements in genetic studies included a variety of weight status measurement tools [3]. In this context, BMI was considered a weak and aggregate phenotype but a reliable measure of \% body fat with an estimated heritability between 0.3 and 0.6 in humans [25]. At the occasion of a Dahlem Workshop in Berlin in 1995, a group of leading obesity experts recommended the use of a range of phenotypes based on body composition as well as considering traits of metabolism and energy intake in genetic studies of any scale [25]. However, during the last 20 years of genetic studies on obesity the tools of molecular biology were mostly applied to crude phenotypes based on BMI and WC only [26-34]. This is contrary to the previously given recommendation [25]. Because $\mathrm{BMI}$ is a clinical score calculated from two biological measures (weight and height), it bears no biological meaning per se [19]. Thus, population studies on the genetics of obesity based on associations between genetic markers and BMI are mostly meaningless. Strictly spoken, the authors of all genetic studies mentioned above searched for the biologic basis of a nonbiological marker. 
Müller et al.: Beyond BMI: Conceptual Issues Related to Overweight and Obese Patients

As to the results published so far, numerous genes that are associated with a high BMI have been identified through genome-wide association studies; however, the proportion of genetically explained variance of BMI was found to be low, and common variants identified have limited clinical value $[30,31,33]$. It is still possible that genetic effects on body composition are likely to be obscured by the use of BMI. As body weight is the sum of the weight of individual organs and tissues (or alternatively, the sum of different body components), each organ (or each body component) has its own internal and genetically based regulation, for example, total body water is regulated by hormones, including antidiuretic hormone (ADH), aldosterone etc., and kidney function; body fat is part of the appetite control system with leptin as a feedback control signal; bone mineral content is regulated by osteocalcin, parathormone and vitamin D; muscle mass is controlled by anabolic factors such as insulin, insulinlike growth factor 1, and testosterone. Since organ and tissue masses are interrelated (e.g., there is a close association between the mass of skeletal muscles and that of bones due to multiple cross-talks), the relationship between organs and tissues also has to be included into a model of body weight regulation. Thus, the genetics of these different regulatory systems cannot be reflected by the suspected 'genetics' of BMI. It is unlikely that replacing BMI by either FM or VAT will increase the effect size of genetic variants. Obviously, future studies on obesity genetics should replace BMI by variables of body composition. Moreover, sound models of body weight regulation must be developed and implemented.

\section{Beyond the BMI: The Issue of Functional Body Composition}

During the last 15 years, three groups of authors recommended to go beyond the BMI [24, $35,36]$. These authors criticized the use of BMI with respect to i) definition and ii) research on metabolic, molecular, and genetic characteristics of obesity. Faced with the variance in obese phenotypes and the complexities of obesity types, the use of BCA rather than of surrogate measures was recommended [35, 36]. Functional body composition refers to the contribution of FM and FFM (or lean tissue) to body functions (e.g., metabolism) and health risks. Since measures of FM per se did not exceed BMI in predicting disease risks (e.g., the relationship between BMI or any measure of FM and insulin resistance is moderate with correlation coefficients ( $\mathrm{r}$ ) between 0.35 and 0.49 , with 0.35 for total VAT volume as assessed by whole body magnetic resonance imaging), it is obvious that obesity needs to be defined by physiological criteria based on body components (e.g., organ and tissue mass, fatty infiltrations of individual organs such as the liver, pancreas, and skeletal muscle) within the context of their related metabolic functions and disease risks [19, 24].

Control of body weight is based on the relationship between tissues and organs and the individual components themselves. This is reflected by the finding that changes in body weight comprise both FFM and FM changes, with a relatively higher contribution of FM to overall weight before weight change [37]. Furthermore, changes of body weight are associated with changes in individual components of either FM or FFM including different regional fat depots, ectopic fat as well as the individual organ mass [38-40].

The concept of functional body composition (FBC) [41] takes into account i) masses of and ii) relationships between individual body components, organs, and tissues as well as iii) their related metabolic and physical functions. Since the functional implication of masses and their interrelationship are included, FBC goes beyond the present state of the art. In our opinion, FBC transfers BMI into daily practice (examples of its clinical application are given in table 1).

Two specific applications relate to FFM and FM. At a group level, FFM is closely related to resting energy expenditure (REE), i.e., REE increases with rising FFM. However, an indi- 
Müller et al.: Beyond BMI: Conceptual Issues Related to Overweight and Obese Patients

Table 1. BCA in clinical practice. Some examples show that going beyond the BMI is related to a question of interest; FBC takes into account masses and their interrelations in the context of their metabolic and physical functions

\begin{tabular}{|c|c|c|c|}
\hline Question & To be measured & Method of choice & $\begin{array}{l}\text { FBC } \\
\text { Body component - function relationships }\end{array}$ \\
\hline $\begin{array}{l}\text { nergy balance? } \\
\text { e.g., 'healthy' weight loss (i.e., loss in } \\
\text { FFM should not exceed } 15 \% \text { of weight } \\
\text { loss), weight re-gain after weight loss } \\
\text { (FM >> FFM?), adherence to diet, effect } \\
\text { of exercise, weight gain as a side effect of } \\
\text { drugs (e.g., insulin, incretin mimetics, } \\
\text { antidepressants) }\end{array}$ & FM, FFM & $\begin{array}{l}\text { ADP, HD, MRI, } \\
\text { QMR, DXA }\end{array}$ & $\begin{array}{l}\text { FM - plasma leptin; } \\
\text { FFM - resting energy expenditure }\end{array}$ \\
\hline $\begin{array}{l}\text { Metabolic risk? } \\
\text { e.g., insulin resistance, lipodystrophy, } \\
\text { metabolically healthy obese patient }\end{array}$ & $\begin{array}{l}\text { liver (ectopic) } \\
\text { fat, VAT, (SAT) }\end{array}$ & $\begin{array}{l}\text { MRI, MRS, CT, } \\
\text { (DXA) }\end{array}$ & liver fat - plasma insulin/insulin resistance \\
\hline $\begin{array}{l}\text { Malnutrition? } \\
\text { e.g., sarcopenic obese patient }\end{array}$ & $\begin{array}{l}\text { muscle mass, } \\
\text { (BIVA?) }\end{array}$ & $\begin{array}{l}\text { DXA, MRI, NA, } \\
\text { TBP, BIA }\end{array}$ & $\begin{array}{l}\text { muscle mass - plasma insulin; } \\
\text { muscle mass - muscle strength - insulin } \\
\text { resistance }\end{array}$ \\
\hline $\begin{array}{l}\text { Osteoporosis? } \\
\text { e.g., osteosarcopenic obese patient }\end{array}$ & bone minerals & DXA, CT, NA & $\begin{array}{l}\text { bone-density - fractural risk - insulin } \\
\text { resistance }\end{array}$ \\
\hline $\begin{array}{l}\text { Hydration? } \\
\text { e.g., obesity-associated co-morbidities, } \\
\text { edema, heart and kidney failure }\end{array}$ & TBW/ECW, BIVA & $\begin{array}{l}\mathrm{D}_{2} \mathrm{O}, \mathrm{NaBr} \\
\text { dilution, BIA }\end{array}$ & $\begin{array}{l}\text { TBW/ECW - blood pressure - insulin } \\
\text { resistance - RAAS }\end{array}$ \\
\hline $\begin{array}{l}\text { Prognosis? } \\
\text { e.g., obese cancer patient }\end{array}$ & $\begin{array}{l}\text { phase angle, } \\
\text { attenuation }\end{array}$ & BIA, CT & $\begin{array}{l}\text { phase angle, muscle attenuation - insulin } \\
\text { resistance, inflammation, hypermetabolism }\end{array}$ \\
\hline \multicolumn{4}{|c|}{$\begin{array}{l}\text { FM = Fat mass; FFM = fat-free mass; VAT = visceral adipose tissue; } \mathrm{SAT}=\text { subcutaneous adipose tissue; } \mathrm{BIVA}=\text { bioelectrical } \\
\text { impedance vector analysis; TBW = total body water; } \mathrm{ECW}=\text { extracellular water; } \mathrm{ADP}=\text { air displacement plethysmography; } \\
\mathrm{HD}=\text { hydrodensitometry; } \mathrm{MRI}=\text { magnetic resonance imaging; } \mathrm{QMR}=\text { quantitative (non-imaging) magnetic resonance; } \mathrm{MRS}= \\
\text { magnetic resonance spectroscopy; } \mathrm{CT}=\text { computer tomography; } \mathrm{DXA}=\text { dual energy X ray absorptiometry; NA = neutron } \\
\text { activation; TBP = total body potassium; D2O2 = deuterium oxide; NaBr = sodium bromide; BIA = bioelectrical impedance } \\
\text { analysis; RAAS = renin-angiotensin-aldosterone system. }\end{array}$} \\
\hline
\end{tabular}

vidual patient may deviate from this association, and his or her residual REE (above or below the regression line between FFM and REE) determines the energetic function of FFM and thus the metabolic status of that patient [41]. As for FM, there is a positive association between FM and plasma leptin levels. Again there is a considerable inter-individual variance in the FM-leptin association, with individual residuals characterizing a functional aspect of FM [41]. In both examples (FFM vs. REE and FM vs. leptin), the function-mass relationship rather than the mass itself reflects what may be called a 'normal' mass. In practice, a considerable variance in masses may then be considered as normal if the function-mass relationship is within a healthy range. From this point of view, we are going to leave behind the era of normative data which are merely based on descriptive epidemiology and add to statistics (i.e., they provide data on the prevalence of overweight etc.). Without taking into account the related body functions, normative data on body weight and body composition are of limited value in clinical research and practice.

FBC can be further extended to the model of healthy body composition (HBC) based on horizontal (i.e., structural at the organ/tissue level) and vertical (e.g. between body compo- 
Müller et al.: Beyond BMI: Conceptual Issues Related to Overweight and Obese Patients

nents, metabolism and its neuroendocrine control) relationships between individual components as well as between components and body functions using mathematical modelling with a hierarchical multi-level multi-scale approach at the software level. HBC then integrates body weight and body composition into overall body systems of cardiovascular, respiratory, hepatic and renal functions. Thus, HBC gives rise to a holistic concept of a weight status taking into account a variety of body component-function relationships.

Going beyond BMI does not simply mean to replace BMI by assessing individual body components. This is also because adjusting weight by stature squared is likely to yield different outcomes for different organs and tissues [42]. With the notable exception of the brain, many components of the human body indeed scale to height with a power close to 2 , but bone and mineral mass, for example, do not $[40,42,43]$. They scale to height with a power greater than 2. FM itself scales to height with a power of 1.8-2.6, depending on both the population of the study and the means of measurement. This issue has not been addressed systematically in children. In 8-year-old children, FFM was optimally adjusted for height by FFM/height ${ }^{2}$, whereas FM was optimally adjusted by FM/height ${ }^{6}$ [44]. Although the bias caused by using FM/height ${ }^{2}$ instead of correct adjustments is considered to be low (this is because height accounted for $<10 \%$ of variation in $\mathrm{FM} /$ height $^{2}$ ), there is a need for a more sophisticated approach.

In summary, the data suggest that $i$ ) body weight and FM may not scale to height with the same power, ii) the power can be different in different populations and age groups, and iii) short and tall subjects with equal BMI, even if they are part of one and the same population, may still have a highly different body composition.

\section{Defining Suitable Body Composition Phenotypes in Obese Subjects}

Evidence against BMI but in favor of body composition analyses also results from the metabolic heterogeneity observed in each of the BMI categories. Recent research focused on the high FM / low muscle mass (i.e., sarcopenic-obese) phenotype compared with the high FM / high muscle mass phenotype [45]. The sarcopenic-obese phenotype was also compared with normal-weight subjects with either normal or low muscle mass (i.e. sarcopenia). Low muscle mass (or even low FFM) was shown to be associated with an elevated health risk, with the highest risk in sarcopenic-obese subjects $[16,46]$. Within the normal-weight population, there are subjects with low subcutaneous adipose tissue (SAT) but increased VAT (i.e., 'Tofi' = thin outside and fat inside) [47]. Despite their normal BMI, these subjects were insulin-resistant and had an increased cardiometabolic risk. The prevalence of metabolically obese individuals within the normal-weight population may be as high as about $24 \%$. Further evidence against the clinical value of BMI comes from recent obesity research on the metabolically healthy obese (MHO) [48, 49]. Obesity is known to be related to numerous metabolic disturbances, but about $50 \%$ of overweight and $15-45 \%$ of obese subjects appeared to have a favorable metabolic profile, i.e., an absence of metabolic complications, inflammation, dyslipidemia, and hypertension. Comparing MHO subjects with obese patients suffering from cardiometabolic risks (i.e., the metabolically abnormal obese (MAO)), both $\mathrm{MHO}$ and MAO subjects had a nearly identical BMI, FM, and SAT. By contrast, MHO subjects showed lower fat infiltration in the liver and in skeletal muscle together with lower mean plasma insulin levels [48].

MHO and MAO subjects cannot be distinguished by BMI. However, strictly spoken, MHO and MAO cannot be referred to as biological entities since they merely reflect the limited accuracy of the BMI in risk prediction. Thus, the status of clinical research on the biological basis of MHO and MAO is questionable. MHO and MAO cannot be considered as important emerging phenotypes. They result from an inappropriate appraisal of BMI in clinical research. 
Müller et al.: Beyond BMI: Conceptual Issues Related to Overweight and Obese

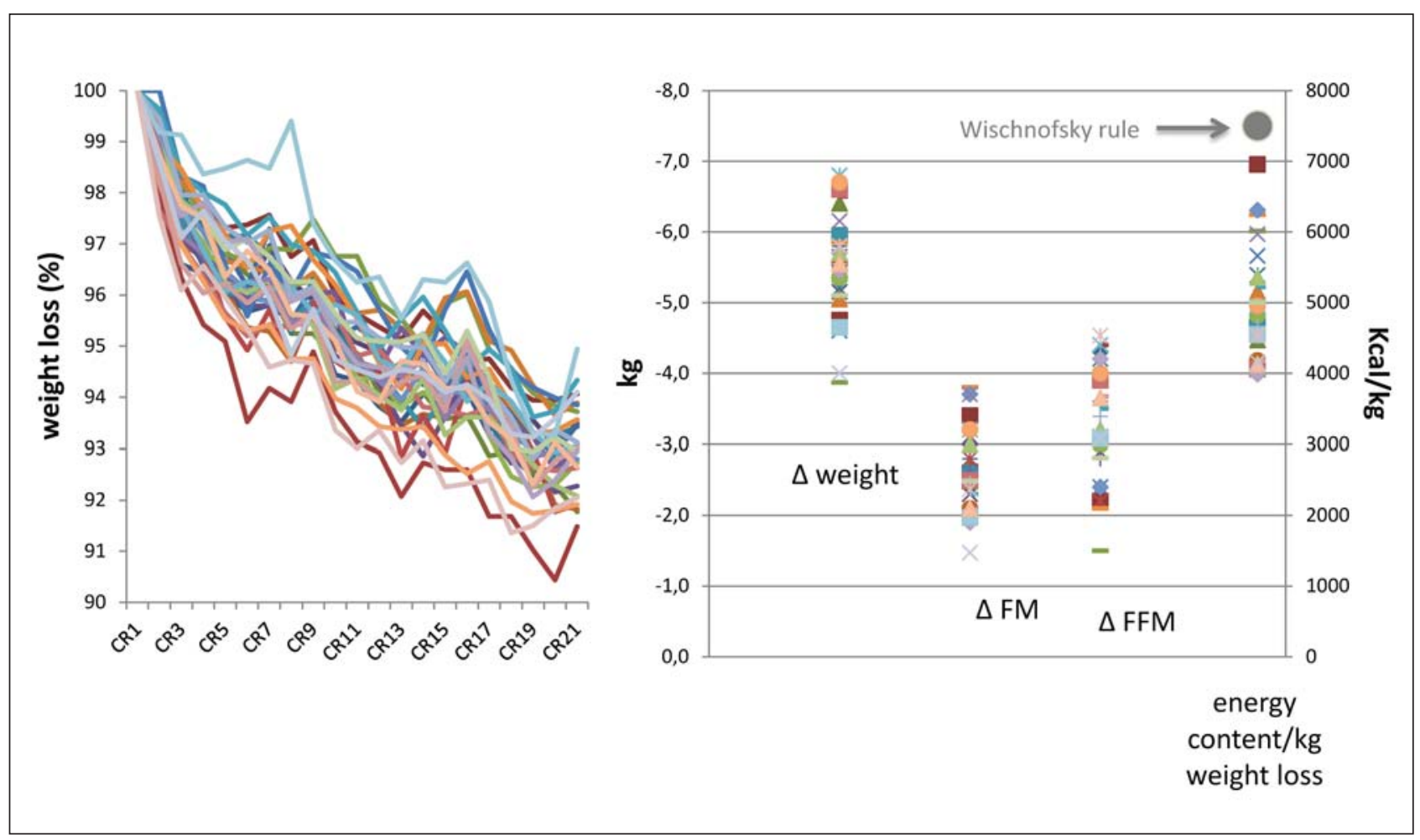

Fig. 5. Individual time courses of weight loss (expressed as percentage of initial body weight) during 21 days of caloric restriction (CR) in response to $\mathrm{CR}$ at $-50 \%$ of individual energy need. Individual day-to-day data on body weight (A) and variance in total changes (CR 21 - CR 1) in FM, FFM, and the energy content of body weight $(\mathbf{C})$ in 32 healthy young normal-weight male volunteers. Despite the controlled approach, there is a considerable variance in weight changes and changes in either FM or FFM. Inter-individual variance in energy content of weight change was high but below the Wischnofsky rule (7,700 kcal/kg, black symbol [50]) suggesting a greater weight loss-associated decrease in FFM. The study protocol is described in detail, and the data were taken from [58].

\section{Weight Loss Treatment}

Body weight and BMI are used to monitor the effects of different strategies for weight management. The process of weight loss shows marked variability, it is slow and gradual. This phenomenon cannot be explained by body weight or BMI. As far as energy balance is concerned, a common rule states that reducing the energy intake by $500 \mathrm{kcal} /$ day or $3,500 \mathrm{kcal} /$ week will lead to a weight loss of $0.45 \mathrm{~kg} /$ week assuming a total energy intake of $7,700 \mathrm{kcal} / \mathrm{kg}$ body weight $[50,51]$. However, in case of a negative energy balance and perfect adherence of subjects to diets, there is a considerable variance among subjects in weight reduction, and weight loss is not linear over time (fig. 5A). Taking into account weight loss-associated changes in body composition, changes in energy content in relation to changes in body weight differ between subjects as well as during the time course of weight loss (fig. 5B). Losses in either FFM (or lean mass) or FM associated with a negative energy balance (and thus the fractional loss of FFM with dieting, exercise, medication, or surgery) provide a mechanistic approach to explain inter-individual variances in weight loss. Applying the common rule (see above), approximately one-fourth of weight loss is due to a loss in FFM [52]. Medical treatment of obese patients aims at a low portion of FFM loss in overall weight loss. However, numerous 
Müller et al.: Beyond BMI: Conceptual Issues Related to Overweight and Obese Patients

factors, such as the level of energy intake, diet composition, sex, baseline FM, inactivity, the metabolic state and the hormonal response to dieting, determine the FFM proportion of overall weight loss. Therefore, assessment of FFM rather than body weight or BMI is central in weight management of obese patients. In order to explain inter-individual variance in weight change during exercise therapy, the importance of assessing FFM in obesity therapy is also obvious as body composition could have changed in favor of FFM [53]. Detailed body composition data are already included in dynamic energy balance models, which are used to predict weight loss in obese patients [54-56].

\section{Future Assessment of Weight Status in Clinical Practice and Research}

Experts involved in the WHO consultation of 2000 had already concluded that 'BMI can be used to estimate the prevalence of obesity within a population and the risks associated with it, but does not, however, account for the wide variation in the nature of obesity between different individuals and populations' [4]. BMI is an imperfect predictor of body composition and disease risks but still has some clinical value as a crude estimate and a first-line categorization of weight status, i.e., to pragmatically decide whom to treat and whom not to treat. However, one should keep in mind that using the BMI carries a considerable risk of misclassification and thus of false conclusions (e.g., in defining the MHO patient).

During the last decades, a so-called revolution in life sciences has created new and partly fundamental dimensions in physiology and medicine. Concomitantly, some basic dimensions (e.g., BMI as a measure of weight status) have been neglected and erroneously been taken as given. It is evident that the use of BMI in genetic and metabolic studies on obesity is of limited value and sometimes misleading. This is due to drawbacks of BMI itself and also due to a lack of a sound concept for body weight regulation. Today, obesity is still defined by statistical rather than physiological criteria [57]. In our opinion, there is a need for a new conceptualization of obesity. In the future, the concept of HBC will replace normal-weight status as defined by BMI. HBC is based on BCA taking into account i) sound models of physiology for body weight regulation and ii) associations between individual body components, cardiometabolic functions and disease risks. HBC will add to a better understanding, improved risk assessment as well as to targeted treatment strategies in overweight and obese patients.

\section{Acknowledgements}

Our own data presented in this manuscript were funded by a grant of the German Ministry of Education and Research (BMBF 0315681), the German Research Foundation (DFG Bo 3296/1-1) and the BMBF Kompetenznetz Adipositas, core domain 'Body composition' (Körperzusammensetzung; FKZ 01GI1125).

\section{Disclosure Statement}

MJM and ABW are consultants of the Seca Company. 
Müller et al.: Beyond BMI: Conceptual Issues Related to Overweight and Obese Patients

\section{References}

1 Quetelet A: Treatise of Man and the Development of His Faculties. Edinburgh, Chambers, 1842.

2 Keys A, Fidanza F, Karvonen MJ, Kimura N, Taylor HL: Indices of relative weight and obesity. J Chron Dis 1972; 25:329-343.

3 Andres R: Mortality and obesity: the rationale for age-specific height-weight tables; in Andres R, Bierman EL, Hazzard WR (eds): Principles of Geriatric Medicine. New York, McGraw-Hill, 1985, pp 311-318.

4 World Health Organization: Obesity: Preventing and Managing the Global Epidemic. WHO Technical Report Series 894. Geneva, WHO, 2000.

5 National Institutes of Health: Clinical guidelines on the identification, evaluation, and treatment of overweight and obesity in adults - an evidence report. Obes Res 1998;6(suppl 2):51S-209S.

6 Cole TJ, Bellizzi MC, Flegal KM, Dietz WH: Establishing standard definition for child overweight and obesity worldwide: international survey. BMJ 200;320:1240-1243.

7 Cole TJ: Weight/height ${ }^{\mathrm{p}}$ compared to weight/height ${ }^{2}$ for assessing adiposity in childhood: influence of age and bone age on p during puberty. Ann Hum Biol 1986;13:433-451.

8 Stergiakouli E, Gaillard R, Tavare JM, Balthasar N, Loos RJ, Taal HR, et al: Genome-wide association study of height-adjusted BMI in childhood identifies functional variant in ADCY3. Obesity (Silver Spring) 2014;22: 2252-2259.

9 World Health Organization Expert Consultation: Appropriate body-mass index for Asian populations and its implications for policy and intervention strategies. Lancet 2004;363:157-163.

10 Prospective Studies Collaboration, Lewington S, Sherliker P, Clarke R, Emberson J, Halsey J, Qizilbash N, Collins R, Peto R: Body mass index and cause-specific mortality in 900000 adults: collaborative analysis of 57 prospective studies. Lancet 2009;373:1083-1096.

11 Sorkin JD: BMI, age, and mortality: the slaying of a beautiful hypothesis by an ugly fact. Am J Clin Nutr 2014; 99:759-760.

12 Jee SH, Sull JW, Park J, Lee SY, Ohrr H, Guallar E, Samet JM: Body mass index and mortality in Korean men and women. N Engl J Med 2006;355:779-787.

13 Zheng W, McLerran DF, Rolland B, Zhang X, Inoue M, Matsuo K, et al: Association between body-mass index and risk of death in more than 1 million Asians. N Engl J Med 2011;364:719-729.

14 Flegal KM, Kit BK, Orpana H, Graubard BI: Association of all-cause mortality with overweight and obesity using standard body mass index categories: a systematic review and meta-analysis. JAMA 2013;309:71-82.

15 Winter JE, MacInnis RJ, Wattanapenpaiboon N, Nowson CA: BMI and all-cause mortality in older adults: a meta-analysis. Am J Clin Nutr 2014;99:875-890.

16 Oreopoulos A, Kalantar-ZadehK, Sharma AM, Fonarow GC: The obesity paradox in the elderly: potential mechanisms and clinical implications. Clin Geriatr Med 2009;25:643-659, viii.

17 Dixon JB, Egger GJ: A narrow view of optimal weight for health generates the obesity paradox. Am J Clin Nutr 2014;99:969-970.

18 Gonzales MC, Pastore CA, Orlandi SP, Heymsfield SB: Obesity paradox in cancer: new insights provided by body composition. Am J Clin Nutr 2014;99:999-1005.

19 Müller MJ, Bosy-Westphal A, Krawczak M: Genetic studies of common types of obesity: a critique of the current use of phenotypes. Obes Rev 2010;11:612-618.

20 Wells JCK: The Evolutionary Biology of Human Fatness. Cambridge, Cambridge University Press, 2009.

21 Pischon T, Boeing H, Hoffmann K, Bergmann M, Schulze MB, Overvad K, et al: General and abdominal adiposity and risk of death in Europe. N Engl J Med 2008;359:2105-2120, erratum in N Engl J Med 2010;362:2433.

22 Yusuf S, Hawken S, Öunpuu S, Dans T, Avezum A, Lanas F, McQueen M, Budaj A, Pais P, Varigos J, Lisheng L; INTERHEART Study Investigators: Effect of potentially modifiable risk factors associated with myocardial infarction in 52 countries (the INTERHEART study): case-control study. Lancet 2004;364:937-952.

23 The Emerging Risk Factors Collaboration: Separate and combined associations of body mass index and abdominal adiposity with cardiovascular disease: collaborative analysis of 58 prospective studies. Lancet 2011;377:1085-1095.

24 Müller MJ, Lagerpusch M, Enderle J, Schautz B, Heller M, Bosy-Westphal A: Beyond the body mass index: tracking body composition in the pathogenesis of obesity and the metabolic syndrome. Obes Rev 2012; 13(suppl 2):6-13.

25 Warden CH, Bouchard C, Friedman JM, Hebebrand J, Hitman GA, Kozak LP, Leibel RL, Price RA, Zechner R: Group report: how can we best apply the tools of genetics to study body weight regulation?; in C Bouchard, GA Bray (eds): Regulation of Body Weight. Biological and Behavioral Mechanisms. Life Sciences Research Reports LS57, Chichester, Wiley \& Sons, 1996, pp 285-305.

26 Frayling TM, Timpson NJ, Weedon WN, Zeggini E, Freathy RM, Lindgren CM, et al: A common variant in the FTO gene is associated with body mass index and predisposes to childhood and adult adiposity. Science 2007; 316:889-894.

27 Hinney A, Nguyen TT, Scherag A, Friedel S, Bronner G, Müller TD, et al: Genome wide association (GWA) study for early onset extreme obesity supports the role of fat mass and obesity-associated gene (FTO) variants. PLoS ONE 2007; 2:e1361.

28 Willer CJ, Speliotes EK, Loos RJ, Lindgren CM, Heid IM, et al: Six new loci associated with body mass index highlight neuronal influence on body weight regulation. Nat Genet 2009;41:25-34. 
Müller et al.: Beyond BMI: Conceptual Issues Related to Overweight and Obese Patients

29 Walley AJ, Asher JE, Froguel P: The genetic contribution to non-syndromic human obesity. Nat Genet 2009;10: 431-442.

30 Speliotes EK, Willer CJ, Berndt SJ, Monda KL, Thorleifson G, Jackson AU, et al: Association analyses of 249796 individuals reveal 18 new loci associated with body mass index. Nat Genet 2010;42:937-948.

31 Sandholt $\mathrm{CH}$, Hansen T, Pedersen 0: Beyond the fourth wave of genome-wide association studies. Nutr Diabetes 2012;2:e37.

32 Loos RJF, Yeo GSH: The bigger picture of FTO-the first GWAS-identified obesity gene. Nat Rev Endocrinol 2014; 10:51-61.

33 Locke AE, Kahali B, Berndt SI, Justice AE, Pers TH, Day FR, et al: Genetic studies of body mass index yield new insights for obesity biology. Nature 2015;518:197-206.

34 Shungin D, Winkler TW, Croteau-Chonka DC, Ferreira T, Locke AE, et al: New genetic loci link adipose and insulin biology to body fat distribution. Nature 2015;518:187-196.

35 Prentice AM, Jebb SA: Beyond body mass index. Obes Rev 2001;2:141-147.

36 Blundell J, Dulloo AG, Salvador J, Frühbeck G; EASO SAB Working Group on BMI: Beyond BMI - phenotyping the obesities. Obes Facts 2014;7:322-328.

37 Forbes GB: Human Body Composition: Growth, Aging, Nutrition and Activity. New York, Springer, 1987.

38 Bosy-Westphal A, Kossel E, Goele K, Later W, Hitze B, Settler U, Heller M, Gluer C-C, Heymsfield SB, Müller MJ: Contribution of individual organ mass loss to weight loss-associated decline in resting energy expenditure. Am J Clin Nutr 2009;90:993-1001.

39 Pourhassan M, Bosy-Westphal A, Schautz B, Braun W, Gluer CC, Müller MJ: Impact of body composition during weight change on resting energy expenditure and homeostasis model assessment index in overweight nonsmoking adults. Am J Clin Nutr 2014;99:779-791.

40 Bosy-Westphal A, Schautz B, Lagerpusch M, Pourhassan M, Braun W, Goele K, Heller M, Gluer C-C, Müller MJ: Effect of weight loss and regain on adipose tissue distribution, composition of lean mass and resting energy expenditure in young overweight and obese adults. Int J Obes 2013;37:1371-1377.

41 Müller MJ: From BMI to functional body composition. Eur J Clin Nutr 2013;67:1119-1121.

42 Müller MJ, Langemann D, Gehrke I, Later W, Heller M, Gluer C-C, Heymsfield SB, Bosy-Westphal A: Effect of constitution on mass of individual organs and their association with metabolic rate in humans - a detailed view on allometric scaling. PLoS ONE 2011;6:e22732.

43 Heymsfield SB, Thomas D, Bosy-Westphal A, Shen W, Peterson CM, Müller MJ: Evolving concepts on adjusting human resting energy expenditure measurements for body size. Obes Rev 2012;13:1001-1014.

44 Wells JCK, Cole TJ; ALSPAC study team: Adjustment of fat-free mass and fat mass for height in children aged 8 y. Int J Obes 2002;26:947-952.

45 Prado CMM, Siervo M, Mire E, Heymsfield SB, Stephan BCM, Broyles S, Smith SR, Wells JCK, Katzmarzyk P: A population-based approach to define body-composition phenotypes. Am J Clin Nutr 2014;99:1369-1377.

46 Prado CM, Lieffers JR, McGagar LJ, Reiman T, Sawyer MB, Martin L, Baracos VE: Prevalence and clinical implications of sarcopenic obesity in patients with solid tumours of the respiratory and gastrointestinal tracts: a population-based study. Lancet Oncol 2008;9:629-635.

47 Thomas EL, Frost G, Taylor-Robinson SD, Bell JD: Excess body fat in obese and normal-weight subjects. Nutr Res Rev 2012;25:150-161.

48 Stefan N, Kantartzis K, Machann J, Schick F, Thamer C, RittigK, Balletshofer B, Machicao F, et al: Identification and characterization of metabolically benign obesity in humans. Arch Intern Med 2008;168:1609-1616.

49 Loos RJF: The metabolically healthy overweight and obese and their impact on all-cause mortality. Obesity (Silver Spring) 2013;21:1750-1752.

50 Wishnofsky M: Caloric equivalents of gained or lost weight. Am J Clin Nutr 1958;6:542-546.

51 Heymsfield SB, Thomas D, Martin CB, Redman LM, Strauss B, Bosy-Westphal A, Müller MJ, Shen W, Nguyen AM: Energy content of weight loss: kinetic features during voluntary caloric restriction. Metabolism 2012;61: 937-943.

52 Heymsfield SB, Gonzales MC, Shen W, Redman L, Thomas D: Weight loss is one-fourth fat free mass: A critical review and critique of this widely cited rule. Obes Rev 2014;15:310-321.

53 Blundell JE, Gibbons C, Caudwell P, Finlayson G, Hopkins M: Appetite control and energy balance: Impact of exercise. Obes Rev 2015;16(suppl 1):67-76.

54 Hall KD, Sacks F, Chandramohan D, Chow CC, Wang YC, Gortmaker SL, Swinburn BA: Quantification of the effect of energy imbalance on body weight. Lancet 2011;378:826-837.

55 Thomas DM, Schoeller DA, Redman LA, Martin CK, Levine JA, Heymsfield SB: A computational model to determine energy intake during weight loss. Am J Clin Nutr 2010;92:1326-1331.

56 Thomas DM, Martin CK, Redman LM, Heymsfield SB, Lettieri S, Levine JA, Bouchard C, Schoeller DA: Effect of dietary adherence on the body weight plateau: a mathematical model incorporating intermittent compliance with energy intake prescription. Am J Clin Nutr 2014;100:787-795.

57 Wells JCK: Commentary: The paradox of body mass index in obesity assessment: not a good index of adiposity, but not a bad index of cardio-metabolic risk. Intern J Epidemiol 2014;43:672-674.

58 Müller MJ, Enderle J, Pourhassan M, Braun W, Eggeling B, Lagerpusch M, Glüer CC, Kehayias JJ, Kiosz D, BosyWestphal A: Metabolic adaptation to caloric restriction and subsequent refeeding: the Minnesota Starvation Experiment revisited. Am J Clin Nutr 2015;102:807-819. 